\title{
Application of High Permittivity Bismuth Copper Titanate in Multilayer Capacitors
}

\author{
D. SZWAGIERCZAK* AND J. KULAWIK \\ Institute of Electron Technology, Kraków Division, Zabłocie 39, 30-701 Kraków, Poland
}

\begin{abstract}
A nonferroelectric high permittivity compound with the perovskite structure, $\mathrm{Bi}_{2 / 3} \mathrm{Cu}_{3} \mathrm{Ti}_{4} \mathrm{O}_{12}$, was synthesized at $900^{\circ} \mathrm{C}$. The ceramic powder and appropriate organic additives were used for preparation of a slurry for tape casting. The obtained green tapes were smooth, flexible, and with a uniform thickness of $25 \mu \mathrm{m}$ after drying at $50^{\circ} \mathrm{C}$. Ag electrodes were screen printed on green rectangular sheets cut by a laser. Subsequent operations were screen printing of $\mathrm{Ag}$ internal electrodes, stacking of green sheets, isostatic lamination, cutting, deposition of external terminations and co-firing of dielectric and conductive layers at $850^{\circ} \mathrm{C}$. Scanning electron microscopy observations showed well sintered, dense, fine-grained microstructure of ceramic layers and good cooperation with the electrodes made of commercial $\mathrm{Ag}$ paste. Capacitance and dissipation factor of multilayer capacitors were examined in the temperature range from -55 to $330{ }^{\circ} \mathrm{C}$ at frequencies $10 \mathrm{~Hz}-2 \mathrm{MHz}$. The fabricated multilayer capacitors exhibit high capacitance and relatively low temperature coefficient of capacitance in the temperature range from -55 to $110^{\circ} \mathrm{C}$. The obtained lead-free high permittivity nonferroelectric material $\mathrm{Bi}_{2 / 3} \mathrm{Cu}_{3} \mathrm{Ti}_{4} \mathrm{O}_{12}$ is a spontaneously formed internal barrier capacitor. This material seems to be a promising alternative for conventional lead-based relaxor dielectrics in multilayer ceramic capacitors.
\end{abstract}

PACS: 77.22.-d, 81.20.-n, 84.32.Tt, 85.40.Xx

\section{Introduction}

Multilayer ceramic capacitors (MLCCs) belong to the most popular passive electronic elements. Small size, high capacitance, high reliability and good high-frequency characteristics are advantages of these capacitors [1-5]. In MLCCs, tens of green dielectric layers fabricated by tape casting with internal electrodes screen printed on their surface are stacked, laminated, and fired in one common process. Typical dielectric compositions for low temperature MLCCs contain lead-based relaxors, such as $\mathrm{Pb}\left(\mathrm{Fe}_{1 / 2} \mathrm{Nb}_{1 / 2}\right) \mathrm{O}_{3}, \mathrm{~Pb}\left(\mathrm{Fe}_{2 / 3} \mathrm{~W}_{1 / 3}\right) \mathrm{O}_{3}$, $\mathrm{Pb}\left(\mathrm{Zn}_{1 / 3} \mathrm{Nb}_{2 / 3}\right) \mathrm{O}_{3}, \mathrm{~Pb}\left(\mathrm{Mg}_{1 / 2} \mathrm{~W}_{1 / 2}\right) \mathrm{O}_{3}$, which can be co-sintered with cheap Ag electrodes at relatively low temperatures.

Lead-free nonferroelectric high dielectric constant materials with perovskite structure and $\mathrm{ACu}_{3} \mathrm{Ti}_{4} \mathrm{O}_{12}$ composition $\left(\mathrm{A}=\mathrm{Ca}, \mathrm{Bi}_{2 / 3}, \mathrm{Y}_{2 / 3}, \mathrm{La}_{2 / 3}, \mathrm{Nd}_{2 / 3}, \mathrm{Sm}_{2 / 3}, \mathrm{Gd}_{2 / 3}\right.$, $\mathrm{Dy}_{2 / 3}$ ) [6-12] could be promising candidates to replace relaxors as dielectrics in MLCCs. These compounds exhibit relatively low sintering temperature enabling co-firing with $\mathrm{Ag}$ electrodes. According to the prevailing opinion, high effective permittivity of these materials is attributed to spontaneous creation of internal and/or surface barrier layer capacitance effects (IBLC and SBLC). Most of the publications concerning these materials have focused on ceramics and thin films. So far, the application

\footnotetext{
* corresponding author; e-mail: dszwagi@ite.waw.pl
}

of $\mathrm{ACu}_{3} \mathrm{Ti}_{4} \mathrm{O}_{12}$ compounds in thick films and low temperature co-fired ceramics (LTCC) technology has been rarely investigated $[7,9]$. The present paper reports on preparation of green tapes based on $\mathrm{Bi}_{2 / 3} \mathrm{Cu}_{3} \mathrm{Ti}_{4} \mathrm{O}_{12}$, as well as on fabrication and characterization of multilayer capacitors with dielectric layers based on this ceramic.

\section{Experimental}

$\mathrm{Bi}_{2 / 3} \mathrm{Cu}_{3} \mathrm{Ti}_{4} \mathrm{O}_{12}$ synthesis was carried out by a conventional solid state reaction at $900^{\circ} \mathrm{C}$ for $5 \mathrm{~h}$. The reaction product was ball milled in isopropyl alcohol for $8 \mathrm{~h}$ and dried. Phase composition of the powder was controlled using an X'Pert Philips diffractometer. Slurries based on $\mathrm{Bi}_{2 / 3} \mathrm{Cu}_{3} \mathrm{Ti}_{4} \mathrm{O}_{12}$ were prepared by ball milling for $3 \mathrm{~h}$ of the inorganic powder mixed with organic additives. Polyvinyl butyral (PVB) was used as a binder, fish oil as a dispersant, polyethylene glycol (PEG400) and dibutyl phthalate as plasticizers, toluene and isopropyl alcohol as solvents. The slip composition is given in Table.

Tapes were fabricated using a R. Mistler tape caster of TTC-1200 type. The slip was poured onto a silicon coated polyester carrier tape placed on a moving belt. The thickness of dielectric tapes was adjusted using a $20 \mathrm{~cm}$ wide doctor blade. Green tapes were dried for a few hours in air flow at room temperature and then at temperature of $50^{\circ} \mathrm{C}$ for $4 \mathrm{~h}$. Further operations comprise: cutting of green sheets by a laser, screen printing of $\mathrm{Ag}$ internal electrodes on green sheets, stacking of 45 dielectric layers, isostatic lamination at a pressure 
TABLE

Slurry composition for tape casting of capacitor dielectric based on $\mathrm{Bi}_{2 / 3} \mathrm{Cu}_{3} \mathrm{Ti}_{4} \mathrm{O}_{12}$.

\begin{tabular}{l|c}
\hline \hline \multicolumn{1}{c|}{ Component } & Content [wt\%] \\
\hline $\mathrm{Bi}_{2 / 3} \mathrm{Cu}_{3} \mathrm{Ti}_{4} \mathrm{O}_{12}$ & 63.9 \\
polyvinyl butyral & 6.1 \\
fish oil & 0.6 \\
polyethelene glycol & 1.6 \\
dibutyl phthalate & 1.4 \\
isopropyl alcohol & 13.4 \\
toluene & 13.0
\end{tabular}

of $20 \mathrm{MPa}$ at $70^{\circ} \mathrm{C}$, dicing of laminates into individual capacitors, deposition of external Ag terminations, burn-out of organic components, and sintering of multilayer capacitors at $850^{\circ} \mathrm{C}$.

Dielectric properties of the multilayer capacitors were determined using a LCR QuadTech meter as a function of temperature in a range from -55 to $330^{\circ} \mathrm{C}$ at frequencies ranging from $10 \mathrm{~Hz}$ to $2 \mathrm{MHz}$. Breakdown voltage of the capacitors was also examined. Seebeck coefficient was measured for bulk $\mathrm{Bi}_{2 / 3} \mathrm{Cu}_{3} \mathrm{Ti}_{4} \mathrm{O}_{12}$ samples in the temperature range $150-800^{\circ} \mathrm{C}$. Microstructure of the dielectric layers and their compatibility with conductive thick films made of a commercial Du Pont 6142D Ag paste were studied using a FEI SEM.

\section{Results and discussion}

The X-ray diffraction analysis confirmed a single phase composition of the synthesized $\mathrm{Bi}_{2 / 3} \mathrm{Cu}_{3} \mathrm{Ti}_{4} \mathrm{O}_{12}$ powder. The obtained dielectric tapes are smooth, flexible, with high tensile strength and a uniform thickness of $25 \mu \mathrm{m}$.

In Fig. 1a the schematic view of a multilayer capacitor is shown. Figure 1b illustrates sheets cut from the fabricated green $\mathrm{Bi}_{2 / 3} \mathrm{Cu}_{3} \mathrm{Ti}_{4} \mathrm{O}_{12}$ tapes, with internal electrodes for 4 capacitors screen printed on each sheet.

(a)

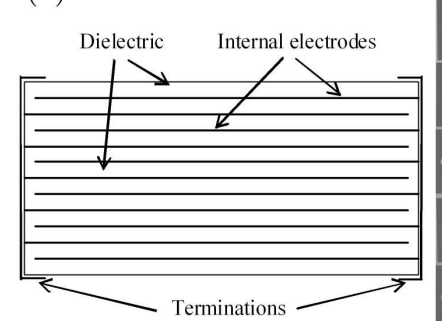

(b)

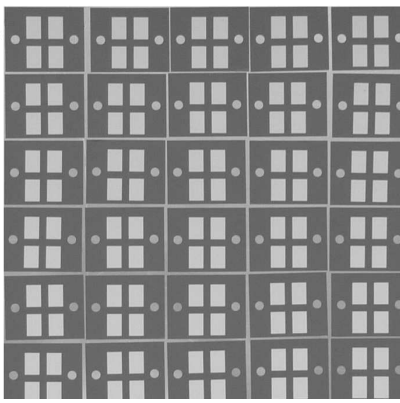

Fig. 1. (a) Schematic view of a multilayer capacitor, (b) green sheets based on $\mathrm{Bi}_{2 / 3} \mathrm{Cu}_{3} \mathrm{Ti}_{4} \mathrm{O}_{12}$ with screen printed Ag internal electrodes.

Figure 2a presents the microstructure of a sintered multilayer capacitor with 45 dielectric layers of
$\mathrm{Bi}_{2 / 3} \mathrm{Cu}_{3} \mathrm{Ti}_{4} \mathrm{O}_{12}$. From Fig. $2 \mathrm{~b}$ it can be seen that the ceramic layers are dense, fine-grained and show good cooperation with the applied Ag electrodes made of the commercial Du Pont 6142D Ag paste. No cracks, delaminations, bubbles or secondary phase inclusions are observed at dielectric-conductive layer boundaries. The shrinkage of the dielectric tapes is $19 \%$ in $x, y$ axes and $25 \%$ in $z$ axis.

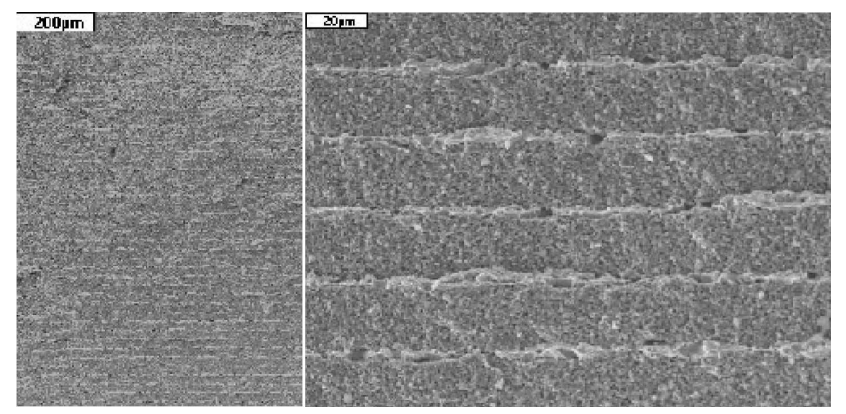

Fig. 2. SEM images of a fractured cross-section of multilayer capacitor with $\mathrm{Bi}_{2 / 3} \mathrm{Cu}_{3} \mathrm{Ti}_{4} \mathrm{O}_{12}$ dielectric layers.

In Fig. 3a and b the specific capacitance of a fabricated capacitor is depicted as a function of temperature and frequency, respectively. As shown in Fig. 3a, the capacitance decreases with increasing frequency and increases with increasing temperature in the range from -55 to $330^{\circ} \mathrm{C}$. There are broad and high maxima in the specific capacitance versus temperature plots, reaching $2.8 \times 10^{3}-1.8 \times 10^{4} \mathrm{nF} / \mathrm{cm}^{3}$ in the investigated temperature range and frequency range $10 \mathrm{~Hz}-1 \mathrm{MHz}$. Figure $3 \mathrm{~b}$ presents $\log -\log$ plot of the frequency dependence of the specific capacitance. At lower frequencies and/or higher temperatures, a capacitance plateau at a level of $10^{4} \mathrm{nF} / \mathrm{cm}^{3}$ occurs which could be attributed to internal barrier layer capacitance effects at grain boundaries. This plateau shifts towards higher frequencies with increasing temperature.

As displayed in Fig. 4a, the examined multilayer capacitors with $\mathrm{Bi}_{2 / 3} \mathrm{Cu}_{3} \mathrm{Ti}_{4} \mathrm{O}_{12}$ dielectric exhibit advantageous low values of temperature coefficient of capacitance, not exceeding $\pm 10 \%$, at $1 \mathrm{MHz}$ in the temperature range from -55 to $110^{\circ} \mathrm{C}$.

In Fig. 4b, the dissipation factor of a fabricated capacitor is presented as a function of frequency in the temperature range $0-200^{\circ} \mathrm{C}$. There are maxima in this plot which shift towards higher frequencies with rising temperature. Dielectric relaxation times $\tau$ determined on the basis of the relationship $2 \pi f_{\max } \tau=1$ (where $f_{\max }$ is frequency corresponding to a dissipation factor maximum) obey the Arrhenius law. The calculated activation energy of dielectric relaxation is $0.49 \mathrm{eV}$. Such a value is in a range typical of many perovskite materials in which charge carriers originate from the ionization of oxygen vacancies formed during thermal treatment at high temperatures. The Seebeck coefficient determined in this work for bulk $\mathrm{Bi}_{2 / 3} \mathrm{Cu}_{3} \mathrm{Ti}_{4} \mathrm{O}_{12}$ ceramic is negative in the 

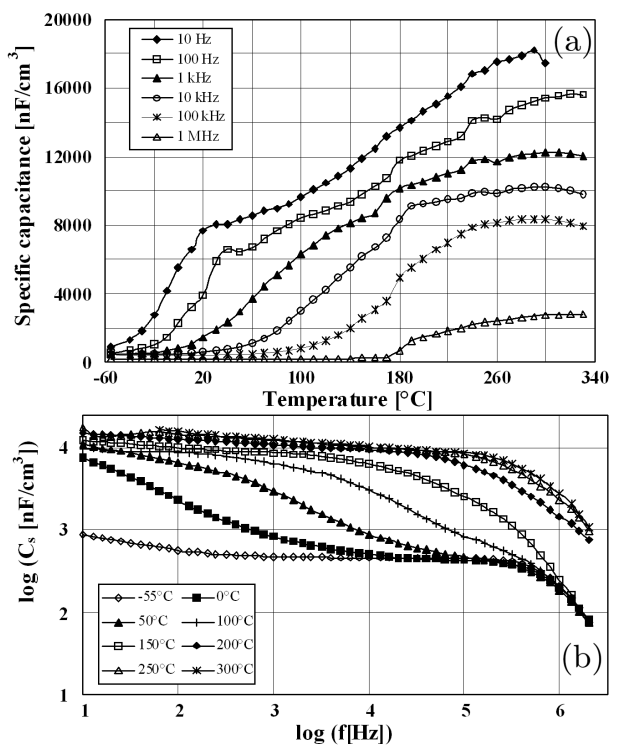

Fig. 3. Specific capacitance $C_{s}$ of a multilayer capacitor with $\mathrm{Bi}_{2 / 3} \mathrm{Cu}_{3} \mathrm{Ti}_{4} \mathrm{O}_{12}$ dielectric (a) versus temperature, (b) versus frequency.
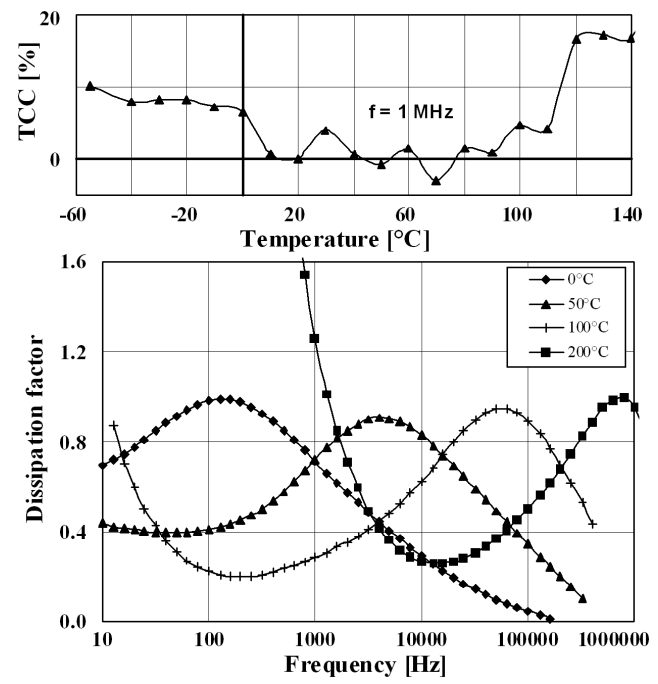

Fig. 4. (a) Temperature coefficient of capacitance in the temperature range from -55 to $140^{\circ} \mathrm{C}$ at $1 \mathrm{MHz}$, (b) dissipation factor versus frequency for a multilayer capacitor with $\mathrm{Bi}_{2 / 3} \mathrm{Cu}_{3} \mathrm{Ti}_{4} \mathrm{O}_{12}$ dielectric layers.

temperature range $150-800^{\circ} \mathrm{C}$. In accordance with the data reported by other authors [11], this result indicates that electrons are dominating charge carriers in the investigated material.

The impedance spectroscopic studies of bulk $\mathrm{Bi}_{2 / 3} \mathrm{Cu}_{3} \mathrm{Ti}_{4} \mathrm{O}_{12}$ ceramic reveal two main dielectric responses, which dominate in different frequency and temperature ranges. The high frequency and low temperature response is related to semiconducting grains and that predominant at low frequencies and high temperatures is attributed to insulating grain boundaries [8-11]. In the dielectric permittivity versus frequency plots there are two plateaus - a very high reaching $10^{5}$ at low frequencies which originates from internal barrier layer capacitance effects and a low one at a level of 200 which occurs at high frequencies and is related to intrinsic properties of the material [9].

Insulating properties of grain boundaries result from preferential reoxidation at grain boundaries region which takes place during cooling process. Semiconducting properties of grains are caused by formation of oxygen vacancies and by changes of oxidation states of copper and titanium ions during sintering.

\section{Conclusions}

A high dielectric permittivity nonferroelectric material $\mathrm{Bi}_{2 / 3} \mathrm{Cu}_{3} \mathrm{Ti}_{4} \mathrm{O}_{12}$ with the perovskite structure similar to $\mathrm{CaCu}_{3} \mathrm{Ti}_{4} \mathrm{O}_{12}$ was applied for fabrication of green tapes and multilayer capacitors. Lead-free composition, high specific capacitance attributed to spontaneous formation of internal barrier layer capacitors during one step firing in air, and low sintering temperature suitable for co-firing with $\mathrm{Ag}$ electrodes are advantages of this material.

\section{Acknowledgments}

The work has been co-financed by the Polish Ministry of Science and Higher Education under grant $\mathrm{N}$ N507468038 and by the Polish National Centre for Research and Development under Eureka project E!4570-IPCTECH.

\section{References}

[1] H. Kishi, Y. Mizuno, H. Chazono, Jpn. J. Appl. Phys. 42, 1 (2003).

[2] A.W. Tavernor, H.P.S. Li, R. Stevens, J. Eur. Ceram. Soc. 19, 1859 (1999).

[3] D.H. Yoon, B.I. Lee, J. Eur. Ceram. Soc. 24, 739 (2004).

[4] D.H. Yoon, B.I. Lee, J. Eur. Ceram. Soc. 24, 753 (2004).

[5] K.H. Hyun, S. Lee, C.W. Cho, U. Paik, D.H. Kim, E.S. Na, J.G. Park, J. Electroceram. 17, 351 (2006).

[6] D.C. Sinclair, T.B. Adams, F.D. Morrison, A.R. West, Appl. Phys. Lett. 80, 2153 (2002).

[7] B. Barbier, C. Combettes, S. Guillemet-Fritsch, T. Chartier, F. Rossignol, A. Rumeau, T. Lebey, E. Durande, J. Eur. Ceram. Soc. 29, 731 (2009).

[8] J. Liu, C.G. Duan, W.G. Yin, W.N. Mei, R.W. Smith, J.R. Hardy, Phys. Rev. B 70, 144106 (2004).

[9] D. Szwagierczak, J. Electroceram. 25, 56 (2009).

[10] W. Hao, J. Hang, Y. Tan, W. Su, J. Am. Ceram. Soc. 92, 2937 (2009).

[11] Y.Q. Tan, J.L. Hang, W.T. Hao, G. Chen, W.B. Su, C.L. Wang, Mater. Chem. Phys. 124, 1100 (2010).

[12] D. Szwagierczak, J. Kulawik, Adv. Sci. Technol. 67, 23 (2010). 